\title{
Presentación: Posverdad
}

Presentation: Post-truth

\author{
Juan-Antonio Nicolás \\ Universidad de Granada \\ jnicolas@ugr.es
}

Arranca con este primer número el proyecto Boletín Veritas, que forma parte de «Veritas. Observatorio de la verdad», una de las iniciativas de la «Cátedra G. W. Leibniz de Filosofía» de la Universidad de Granada. Se publica en Monograma. Revista Iberoamericana de cultura y pensamiento, a cuya dirección agradecemos esta acogida. Se publica también en la página web de la Cátedra (www.leibniz.es/boletin-veritas).

Se trata de una publicación de información bibliográfica cuyo objetivo es seleccionar, valorar y difundir información sobre publicaciones recientes de carácter filosófico, y especialmente en el ámbito de temas relacionados con la verdad. Muchas de las revistas especializadas de filosofía contienen alguna parte relacionada con publicaciones recientes, pero no existe ninguna, hasta donde conocemos, dedicada exclusivamente al comentario y difusión bibliográficos.

En la era de internet el acceso a la información ha cambiado completamente su funcionamiento. En épocas anteriores (hace solamente cuatro o cinco décadas) el problema para la investi- 
gación filosófica era el acceso a la información. En los pocos países de vanguardia en el desarrollo tecnológico este problema estaba relativamente bien solucionado, pero para el resto del mundo suponía un grave problema en muchos casos insalvable. Poder acceder a la información necesaria para la investigación requería de costosas peregrinaciones (personal y materialmente) hasta los centros de excelencia. En muchos casos estas dificultades eran sencillamente insalvables.

Hoy la situación ha cambiado notablemente, aunque lo descrito anteriormente aún no ha desaparecido ni mucho menos. internet ha cambiado radicalmente las posibilidades reales de difusión y de acceso a la información. Esto a su vez ha planteado problemas inexistentes anteriormente, como todo desarrollo tecnológico. Pero ciertamente ha conseguido hacer llegar la información mucho más allá de los límites implicados en las tecnologías basadas en la imprenta. En este sentido internet ha supuesto para la humanidad una revolución quizás equivalente a la de la propia imprenta.

Internet ha desencadenado la aparición de toda una serie de tecnologías que han conseguido facilitar y ampliar tanto la transmisión de la información como el acceso a la misma. Y en unas condiciones de accesibilidad material impensables hace tan solo unas pocas décadas. En virtud de ello, y prescindiendo ahora de otros problemas generados, buena parte de la población (aún estamos lejos de que sea la totalidad de la humanidad) tiene hoy acceso a la información, a mucha información, a mucha más información de la que se puede procesar y asumir.

Y he aquí que la situación se ha invertido. Ahora el problema para grandes masas de población y también para gran cantidad de investigadores ya no es el acceso a la información, sino justamente el exceso de información disponible. Ahora el reto ya no

Nicolás, Juan-Antonio (2021). «Presentación: Posverdad». Monograma. Revista Iberoamericana de Cultura y Pensamiento, n. ${ }^{\circ}$ 8, pp. 227-230. doi: 10.36008/monograma.2021.08.3015. http: revistamonograma.com. ISSN: 2603-5839. 
es conseguir la información, sino valorarla, criticarla y seleccionar aquello que pueda resultar más valioso en cada caso.

Justamente en esta coyuntura se inserta el Boletín Veritas. Quiere contribuir a conocer y a valorar publicaciones recientes de filosofía y en concreto del entorno de la verdad; y con ello se quiere ayudar a mantener vivo el diálogo filosófico y abordar problemas que la sociedad tiene planteados, desde el punto de vista de la comunidad de investigación en filosofía.

La problemática general pero específica del Boletín es el tema de la verdad con sus múltiples formulaciones teóricas, diversidad de niveles, relaciones con otras temáticas, implicaciones para multitud de problemas o ámbitos filosóficos, etapas de desarrollo histórico, presencia de corrientes filosóficas, etc. En cada número del Boletín se selecciona un tema concreto y se le confiere una estructura en tres partes. Primera, una entrevista a algún investigador relevante en relación con el tema seleccionado. Segunda, reseña de varios libros o publicaciones significativas cuyo contenido es sometido a análisis y valoración crítica. Y tercera, listado de bibliografía reciente y seleccionada de la cual se ofrece un resumen del contenido.

En este primer número se ha elegido el tema «posverdad», un fenómeno que plantea problemas graves en ámbitos sociales muy diversos. Aunque el tema en cuanto problemática específica y así formulada es muy reciente, va habiendo ya bastantes publicaciones y un importante debate entre especialistas de diferentes disciplinas. Esta diversidad se ha querido reflejar, en la medida de lo posible, en la selección bibliográfica que se presenta.

Se incluye una entrevista a Santiago Carbó, catedrático de economía de la Universidad de Granada, especializado en análisis financiero y con amplio reconocimiento internacional. Se 
interesa por la problemática de la posverdad en cuanto afecta directamente al mundo de la banca y las finanzas. Le agradecemos que haya accedido a esta entrevista con Boletin Veritas.

Esperamos que Boletín Veritas resulte un instrumento útil a investigadores e interesados en los problemas filosóficos y agradecemos una vez más a la dirección de Monograma que haya acogido estas páginas en su revista. 